\title{
Information Polity: International recognition and more excellent papers
}

I am pleased to begin with my recent statement, which some of you will already have read, relating to newfound recognition for Information Polity. It is a major moment in the life of what is still a new journal when recognition is offered by a major international bibliometrics provider - in this case SCOPUS.

Scopus describes itself as "the largest abstract and citation database of peer-reviewed literature: scientific journals, books and conference proceedings. Delivering a comprehensive overview of the world's research output in the fields of science, technology, medicine, social sciences, and arts and humanities, Scopus features smart tools to track, analyze and visualize research".

You will read in my announcement below what this SCOPUS recognition means for Information Polity.

"IOS Press and I have received some excellent news from SCOPUS , the publisher Elsevier's academic journals database. They use the SCImago measurement tool based upon journal citations over successive two year periods. Information Polity went into SCOPUS 2 years ago and is already in the top quartile of journals worldwide for 4 of our targeted subject fields:

- Top quartile in Public Administration in 2013;

- Top quartile in Sociology \& Political Science in 2013;

- Top quartile in Communication in 2012 \& 2013;

- Top Quartile in Geography, Planning \& Development in 2011, 2012 \& 2013;

- Second quartile in Information Systems in 2011, 2012 \& 2013.

As many of you know we publish strongly in the IS field and I would expect us to be recognised as top quartile in the near future.

For the details have a look at: http://www.scimagojr.com/journalsearch.php?q=21100200653\&tip=sid \&clean $=0$.

This is of course excellent news for those of you who have published and aim to publish in Information Polity.

Please help me in ensuring that Information Polity is recognised in all the subject area listings important to you such as those for the Business Schools."

In the meantime keep your excellent papers coming in and let us have them cited as often as possible!

\section{Papers in our final edition of 2014}

I am delighted with what is a most interesting final edition of Information Polity 2014, covering as it does a mixed bag of subjects within our field. The first of these is the really 'hot topic' of big data. Written by Rashmi Krishnamurthy and Professor Kevin C. Desouza from the School of Public Affairs 
at the University of Arizona it is a paper full of insights into the practical world of public administration as it 'confronts' the potential of big data analytics.

Specifically, the authors have examined the United States Social Security Administration (SSA), known as the "face of the government," as it collects, manages, and curates massive volumes of data relating to social security provision to US citizens. No other federal agency has such a large scale "relationship brief' with US citizens. The authors track the agency's work on its legacy systems; on upgrading its employee capabilities as well as its consumers' ability to use the systems; implementing data management strategies and organizational architecture; on balancing security and privacy issues; and its advocacy for scaled up investment in big data analytics. All of this represents a major upheaval in the world of public administration yet the authors say that the Agency remains only at the early stages of fully exploiting big data.

This paper is striking in many respects, one of which is when we get a close sense of what big data means in terms of computing scale. I quote: "The agency's servers can hold nine petabytes of data, while its open, client server contains 12 petabytes of data. Additionally, the agency is accessible to citizens through a multitude of mediums such as telephone, online, and traditional mail". And, of course, the Agency has highly active Twitter and Facebook accounts also with all that implies for data and communications management. These and other orders of magnitude have to be held in mind when we are thinking of how a large part of public administration, with all its traditional practices, comes to terms with this brave new informational world. For those of you who read my editorials my advice is simple. Here is a subject that we all need to understand better and here is a paper that I say emphatically will help all of us to do so.

Most of the papers in this edition are concerned with aspects of public administration and I shall review those later. But first let me turn to the second paper in this edition, an outstanding article majoring on women's politics in Turkey from Rabia Karakaya Polat and Elif Çağlı from Işık University's Department of International Relations, Istanbul. The authors state that to date there has been little "systematic research addressing the question of how Turkish WNGOs [Women's Non Governmental Organisations] use the Internet to achieve their mission and goals." Their paper aims to fill that gap by focusing upon an organization [a WNGO] whose mission is to improve and augment and thereby support the candidacy of women in Turkish politics. This organization is known as Ka-der (Association for the Support of Women Candidates).

Like the first paper in this edition this one also provides for a rich understanding of information and communication as used by this organization. Also, like the first paper it is a brilliantly contextuated case study of a single organisation. And, finally like the first paper, it has applicability for many others in the field and for the scholars that study and write about them.

In their concluding remarks the authors show how the Internet has affected Ka-Der. It is a concisely written summary of findings that repays reading carefully not least for its measured, practice related descriptions which include emphasis upon the usefulness of the more mundane applications facilitated by the Internet. Much in the way of hubris surrounds so much internet literature and I for one find it refreshing when authors are able to conclude that a major political organisation continues to appreciate and promote the face-to-face of coffee drinking as well as the exotic, virtual worlds that this journal aims largely to understand better.

Case studies abound in this collection of papers and the third of them is a study of the Belgian city of Mechelen and, specifically, attempts in that city to engage in sustained 'strategic alignment' of IT systems and business processes. I am delighted to inform readers that this paper was awarded the Annual IOS Press/Information Polity prize for work on IT and public administration at the 2014 meeting of the European Group of Public Administration. 
Twenty and more years ago this study would have engaged with the concept of BPR [business process re-engineering] as its major intellectual anchor. Then, in the early 1990s, a belief system grew up around BPR that, with the right strategic management, IT systems could and should be used to deconstruct and reconstruct organisations in all sectors, including those in the public sphere. A new form of public administration would emerge exhibiting reduced levels of organisational hierarchy and consumer centricity leading as well to massive efficiency and effectiveness gains. Now, 20 years on Simon Vander Elst and Filip De Rynck from the University of Ghent, Belgium help us to understand contemporary thinking about IT systems and organizational realignment. Their approach takes us away from top down strategic alignment thinking, such as that which characterised BPR, and towards interpretive subtlety in the way we envisage the interplay of organization and IT systems. They are concerned that to understand fully what happens in complex governmental organizations following the introduction of major new ICT initiatives we must look at the whole organization, from top to bottom, looking at different interpretive schemes at different levels and units which present more diverse outcomes from strategic change than the classical top down model would admit. And crucially to arrive at this improved understanding scholars should study an organization longitudinally. As organizations move through time, adjusting and resisting at different levels as they go, so institutional character is revealed and big strategic, top down, initiatives seem doomed to fall short of clear-eyed top down managerial expectations.

Our next paper breaks us away from case studies and into a wider scale empirical study of City government websites in the US. Here the authors, James Vanderleeuw and Jason C. Sides, both from Lamar University, Beaumont, Texas ask just what it is that city websites are promoting. Engagingly they have the chutzpah to ask "do they promote anything at all?"! These authors examine the websites of 345 cities in the state of Texas and conclude that for the most part these sites are not used to promote the city from a strategic perspective. Hence the bold question that I quote above. Particularly surprising is that, counter to much of the literature, these sites are not being developed in ways that has their content matching economic development goals of the city. In concluding their study Vanderleeuw and Sides argue that the fate of US cities will increasingly lie in their own hands. They cite the bankruptcy of Detroit to give weight to the point yet, as they show, analysis of city websites suggests that cities are not grasping this survival need. I hope that these authors are engaging widely within Texas and perhaps more widely in the US, at least, on their findings. They have conducted a thoroughly enlightening piece of work from which practical lessons can and should be learnt.

For our fifth paper of this edition we return to case study research. We have thus far carried a case study of big data in big government, a case of an NGO with political development for women as its goal and a case study of a Belgian city government depicting the complexities attaching to understanding and implementing organisational change. Now, for this paper we turn to a case study of a major information systems development. These authors, Özel Sebetci and Gökhan Aksu from Adnan Menderes University, Turkey examine the 'e-movable system'. This system, adopted across the Turkish public sector, supports inventory management within all organisations, specifically supporting procurement, utilisation and onsale of goods held within these organisations. The core question that these authors ask is "how do we measure the success of this system' and their answer is to use a 'technology acceptance model' of evaluation comprised of seven elements - "information quality, service quality, perceived usefulness, perceived ease of use, attitude towards using and behavioural intention to use."

These authors demonstrate the utility of the e-movable system, arguing indeed for an extension of its use into the business sector also. Most interestingly in this e-government study is the iterative and cumulative relationship of the seven factors examined within the TAM. Thus a positive opinion on one factor tends to produce a positive opinion on the next factor and so on. There is surely a general message here for the implementation of successful information systems. 
I am pleased that we are able to publish two further papers in this edition. They derive from the workshop "Rethinking Information Systems in the Public Sector: Bridging Academia and Public Service" held earlier this year in Tel Aviv, Israel. The workshop was held in conjunction with the European Conference on Information Systems (ECIS 2014), and is part of the activities of the Special Interest Group for eGovernment (SIGeGov) of the Association for Information Systems (AIS).

An introduction to these two papers is to be found in the journal. It is authored by Rony Medalgia from the Copenhagen Business School, Denmark.

John Taylor, November, 2014 